Brazilian Journal of Microbiology (2009) 40: 893-900

ISSN 1517-8382

\title{
ISOLATION AND IDENTIFICATION OF PROFENOFOS DEGRADING BACTERIA
}

\author{
Saadatullah Malghani ${ }^{\dagger}$, Nivedita Chatterjee ${ }^{\dagger}$, Hu Xue Yu ${ }^{*}$, Zejiao Luo ${ }^{1}$
}

Key Laboratory of Biogeology and Environmental Geology, Ministry of Education (BGEG), School of Environmental Studies, China University of Geosciences, 388 Lumo Road, Wuhan, Hubei 430074, China .

Submitted: November 27, 2008; Returned to authors for corrections: March 23, 2009; Approved: July 14, 2009.

\begin{abstract}
An enrichment culture technique was used to isolate bacterial strains responsible for the biodegradation of profenofos in a soil from Hubei province of central China. Two pure bacterial cultures, named W and Y, were isolated and subsequently characterized by sequencing of 16S rRNA genes and biochemical tests. Isolate W showed $96 \%$ similarity to the $16 \mathrm{~S}$ rRNA gene of a Pseudomonas putida unlike Y which showed $99 \%$ similarity to the 16S rRNA gene of Burkholderia gladioli. Both strains grew well at pH 5.5-7.2 with a broad temperature profile ranging from $28^{\circ}$ to $36^{\circ} \mathrm{C}$. Bioremediation of profenofos-contaminated soil was examined using soil treated with $200 \mathrm{ug} \mathrm{g}^{-1}$; profenofos resulted in a higher degradation rate than control soils without inoculation. In a mineral salt medium (FTW) reduction in profenofos concentration was $90 \%$ within 96 hours of incubation. A literature survey revealed that no data is available regarding the role of Burkholderia gladioli on pesticide biodegradation as well as on profenofos.
\end{abstract}

Key words: Profenofos, Organophosphate pesticide, Gas Chromatography, Bioremediation.

\section{INTRODUCTION}

Profenofos, a well known organophosphate pesticide has been in agricultural use over the last two decades for controlling Lepidopteron pests of cotton and tobacco. Profenofos has been classified as a moderately hazardous (Toxicity class II) pesticide by the World Health Organization (WHO) and it has a moderate order of acute toxicity following oral and dermal administration $(32,33)$. Profenofos is extremely toxic to fish and macro- invertebrates (1). The acute toxic action of profenofos is the inhibition of the acetylcholinesterase activity (11) resulting in toxicity also in humans (8). Microbial degradation of organophosphate pesticides is of particular interest because of the high mammalian toxicity of such compounds and their widespread and extensive use. The most significant step in detoxifying organophosphate compounds is hydrolysis since that makes the compounds more vulnerable to further degradation (21). The enzyme responsible for catalyzing this reaction is referred as an esterase or phosphotriesterase. Research has found a wide range of microorganisms possessing the organophosphate hydrolase enzyme $(9,18,24)$. The most well-known examples of natural isolates able to degrade organophosphates are Pseudomonas diminuta $\mathrm{MG}$ and Flavobacterium ATCC 27551. They have been shown to possess the organophosphate hydrolase $(\mathrm{OPH})$ enzyme (23).

*Corresponding Author. Mailing address: Key Laboratory of Biogeology and Environmental Geology, Ministry of Education (BGEG), School of

Environmental Studies, China University of Geosciences, 388 Lumo Road, Wuhan, Hubei 430074, China.; E-mail: huxueyu@cug.edu.cn

$\dagger$ Both are equal first authors 
The effects of profenofos on total bacterial populations were supposed significant but studies showed that microbial populations decreased initially at concentrations of 100 to $300 \mu \mathrm{g} \mathrm{g}^{-1}$ but recovered rapidly to levels similar to those in the control (22) indicating that it can serve as Carbon source. Phototransformation of profenofos studies showed cleavage of ester bond (35). To our knowledge, degradation of profenofos by a soil bacterium has not been reported earlier. This paper describes the enrichment, isolation and identification of profenofos degrading bacteria.

\section{MATERIALS AND METHODS}

\section{Reagents and Chemicals}

Technical-grade profenofos (99.5\% pure) was purchased from Guangzhou Webber Chemical Co., Ltd. , HPLC grade acetone and hexanes were supplied by J.T Baker, USA and Mallinckrodt Baker Inc TEDIA, USA, respectively. Enzymes, marker and Buffer for PCR were obtained from Sangon Shanghai, China. All other chemicals, if not otherwise stated, used for media were purchased from Sinopharm Chemical Reagent Co. Ltd. (SCRC), Shanghai, China.

\section{Sample Collection for Enrichment Studies}

Two environmental samples were used in this study for the isolation of profenofos-degrading microorganisms. Both soil samples (Table-1) were collected from different sites with a history of 6-7 years of profenofos applications in Hanchuan city of Hubei province, China. The coordinates of the sampling site were $30^{\circ} 40^{\prime} 59.7^{\prime \prime} \mathrm{N}, 113^{\circ} 49^{\prime} 37.3^{\prime \prime} \mathrm{E}$. The collected samples were stored at $4^{\circ} \mathrm{C}$.

Isolation of profenofos-degrading bacteria by enrichment culture

\section{Medium for isolation}

Salt medium FTW (15) with the following composition was used: ( $\mathrm{g} \mathrm{L}^{-1}$ deionized water) $\mathrm{K}_{2} \mathrm{HPO}_{4}$ 0.225; $\mathrm{KH}_{2} \mathrm{PO}_{4}$ 0.225; $\left(\mathrm{NH}_{4}\right)_{2} \mathrm{SO}_{4}$ 0.225; $\mathrm{MgSO}_{4} \cdot 7 \mathrm{H}_{2} \mathrm{O} \quad 0.05 ; \mathrm{CaCO}_{3}$ 0.005; and $\mathrm{FeCl}_{2} \cdot 4 \mathrm{H}_{2} \mathrm{O} \quad 0.005$, blended with $1 \mathrm{~mL}$ of Focht trace elements solution (10). The Focht trace element solution contained (mg L$\left.{ }^{-1}\right): \mathrm{MnSO}_{4} \cdot \mathrm{H}_{2} \mathrm{O} \quad 169 ; \mathrm{ZnSO}_{4} \cdot 7 \mathrm{H}_{2} \mathrm{O}$ 288; $\mathrm{CuSO}_{4} \cdot 5 \mathrm{H}_{2} \mathrm{O} \quad 250 ; \quad \mathrm{NiSO}_{4} \cdot 6 \mathrm{H}_{2} \mathrm{O} \quad 26 ; \mathrm{CoSO}_{4} \quad 28 ;$ and $\mathrm{Na}_{2} \mathrm{MoO}_{4} \cdot 2 \mathrm{H}_{2} \mathrm{O} 24 ; \mathrm{pH}-7.2 \pm 0.2$.

The medium for isolation was composed of FTW and profenofos. FTW was autoclaved and then supplemented with $100 \mathrm{mgL}^{-1}$ profenofos. Plates for isolation were prepared by adding $20 \mathrm{~g}$ agar per liter of isolation medium.

Luria-Bertani (LB) Medium composition was: $\left(\mathrm{g} \mathrm{L}^{-1}\right.$ deionized water) $\mathrm{NaCl} \mathrm{10.0;} \mathrm{Tryptone} \mathrm{10.0;} \mathrm{Yeast} \mathrm{extract} \mathrm{5.0;}$ pH- $7.2 \pm 0.2$ (28).

\section{Isolation procedure}

The isolation method of Lansing M. Prescott, 2002, was followed with some modifications. The soil samples (Table1) were sieved through a 90-mesh sieve to remove stones and plant material. Then $10 \mathrm{~g}$ of soil was placed in a $250 \mathrm{~mL}$ conical flask containing $100 \mathrm{~mL}$ FTW media and incubated at $30^{\circ} \mathrm{C}$ in a rotary shaker at $150 \mathrm{rpm}$ for two days. The flasks were then left for a few hours to allow the soil particles to settle, and the suspension containing microorganisms was then used to inoculate fresh sterilized FTW media containing $100 \mathrm{mgL}^{-1}$ profenofos and incubated for two days.

To obtain pure cultures of single strains, $5 \mathrm{~mL}$ aliquots of enrichment cultures were centrifuged at $3000 \mathrm{rpm}$ for $5 \mathrm{~min}$ (TGL-16A centrifuge, Changsha Pingfan instrument Ltd) and the cell pellets were resuspended in $2 \mathrm{~mL}$ sterile media. Aliquots of this suspension were streaked on FTWprofenofos agar plates. Inoculated plates were incubated under aerobic conditions at $30^{\circ} \mathrm{C}$ and discrete colonies were isolated.

The resulting colonies were repeatedly subcultured in the same medium (FTW with $100 \mathrm{mgL}^{-1}$ of profenofos) to confirm their profenofos utilizing ability. All colonies were transferred into fresh sterile medium to obtain a pure culture. Two strains, designated $\mathrm{Y}$ and $\mathrm{W}$, which possessed the highest degradation capability, were selected for further investigation (26). 


\section{Identification of the isolates}

The morphological, physiological and biochemical tests of isolates $\mathrm{W}$ and $\mathrm{Y}$, were performed by using standard methods. The bacterial strains were taxonomically identified from Bergey's Manual of systematic bacteriology (12) as Pseudomonas sp. and further confirmation was made by sequencing $16 \mathrm{~S}$ rRNA gene.

Genomic DNA isolation and sequencing of $16 \mathrm{~S}$ rRNA gene

Genomic DNA was isolated using standard bacterial procedures (14). The following primers were used for PCR amplification of the gene encoding 16S rRNA: 63f (5'AGGCCTAACACATGCAAG TC-3'), 1387r (5'GGgCGGAGTGtACAAGGC-3') . The PCR mixtures $(50 \mu \mathrm{l})$ contained $10 \mu \mathrm{M}$ of each primer, PCR buffer, $5 \mathrm{U}$ of Taq DNA polymerase, BSA $10 \mu \mathrm{M}$ and $2 \mu \mathrm{l}$ of DNA. The thermocycling conditions consisted of a denaturation step at $94^{\circ} \mathrm{C}$ for $3 \mathrm{~min}, 28$ amplification cycles of $94^{\circ} \mathrm{C}$ for $20 \mathrm{~s}$, $58^{\circ} \mathrm{C}$ for $40 \mathrm{~s}$ and $72^{\circ} \mathrm{C}$ for $1 \mathrm{~min}$ and a final polymerization for $3 \mathrm{~min} 30 \mathrm{~s}$ with a MJ Research Thermalcycler (MJ Research, PTC-100, USA). PCR products were visualized on 1.0\% agarose gels with Gel Doc 2000 (Bio-Rad USA). The purified PCR products were then cloned into the pMD-18 T vector (TaKaRa, Dalian, China) and sequenced in Sangon Shanghai, China. Nucleotide sequence similarities were determined using BLAST (National Center for Biotechnology Information databases).

\section{Biodegradation studies}

\section{Inoculums preparation for degradation studies}

The isolated bacterial cells were pre-cultured in LB medium at $30^{\circ} \mathrm{C}$ with $150 \mathrm{rpm}$ shaking, harvested by centrifugation at $6000 \mathrm{rpm}$ for $10 \mathrm{~min}$ and washed three times with sterilized water. For all experiments, cells were used at a concentration of $20 \mathrm{mg}$ dry weight per $50 \mathrm{~mL}$ media and for $50 \mathrm{~g}$ soil $40 \mathrm{mg}$ dry weight cells were used. If not otherwise stated the incubation conditions were $30^{\circ} \mathrm{C}$ with $150 \mathrm{rpm}$ shaking.

\section{Kinetics of biodegradation}

The degrading ability of the isolated strains was assayed with batch cultures in mineral salts medium (FTW) supplemented with profenofos $\left(100 \mathrm{mgL}^{-1}\right)$ in triplicates. The cultures were inoculated with the isolated strain and incubated. Aliquots of $2 \mathrm{~mL}$ were taken at suitable interval between 0 to 4 days and were subjected to GC analysis after extraction of profenofos residues. Triplicate sets of each composition without inoculation were kept as controls.

\section{Degradation studies in soil}

Air-dried sieved $(<2 \mathrm{~mm})$ soil samples, used for isolation (Table-1), were placed in $50 \mathrm{~g}$ portions in presterilized $100 \mathrm{~mL}$ Erlenmeyer flasks and were moistened with sufficient water to provide $60 \%$ water holding capacity. The soil samples were amended with $200 \mathrm{mg} / \mathrm{L}$ of profenofos and inoculated with the isolates separately and incubated in duplicate. The duplicate sets of controls consisting of sterilized soil with identical amount of profenofos but without the isolate were run simultaneously under identical conditions. At different time points between 0 to $25 \mathrm{~d}$., aliquots of $3 \mathrm{~g}$ soil were removed in duplicate from the microcosms and subjected to extraction of profenofos residues in soil samples by acetone-hexane (20:80) mixture (17) and then analyzed by GC.

\section{Gas chromatography analysis}

Extraction of profenofos residues: The samples (aliquots of liquid culture as well as soil) were subjected to organic solvent extraction three times with acetone: hexane (20:80) mixture. The extract was filtered and the organic solvents were evaporated to near dryness on a rotary thin film evaporator. The residues were dissolved in $5 \mathrm{ml}$ hexane and stored at $4^{\circ} \mathrm{C}$ until analysis. Efficiency of extraction and estimation of profenofos was over $90 \%$.

GC-ECD : Profenofos residues, extracted in hexane from salt media or from the soil samples, were analyzed in Agilent Gas chromatograph (Model 6890 Series USA) equipped with a Ni 63 electron capture detector with HP-5MS column 
(length $30 \mathrm{~m}$, diameter $0.25 \mathrm{~mm}$ ). The operating conditions: initial temperature $120{ }^{\circ} \mathrm{C}$, then heated at $7^{\circ} \mathrm{C} / \mathrm{min}$ to a final temperature of $250^{\circ} \mathrm{C}$. The total run time was $33.07 \mathrm{~min}$. The splitless mode was used for the injection. The injector temperature was at $240^{\circ} \mathrm{C}$ and the detector temperature was at $300^{\circ} \mathrm{C}$. Nitrogen gas $(99.999 \%)$ was used as the carrier gas with a gas flow at $23.3 \mathrm{~cm} \mathrm{sec}^{-1}$ linear velocity.

\section{RESULTS}

Isolation and Identification of profenofos degrading bacteria

Four different microorganisms were isolated from the profenofos-exposed soil samples by above mentioned method. All isolates were found to possess the ability to degrade the pesticide. Strains named as W and Y degraded profenofos were subejected for further studies and are presented in this study. Theses strains were a rod-shaped, gram negative, motile bacterium (Table 1).

By sequencing the 16S rRNA gene of $\mathrm{W}$ and $\mathrm{Y}$ and comparing them with previously published $16 \mathrm{~S}$ rRNA gene sequences, the strains were classified as a member of the genus Pseudomonas and Burkholderia respectively. The sequence of strain $\mathrm{W}$ displayed the highest identity (96\%) with the 16S rRNA gene of a Pseudomonas putida (FJ865579) and strain Y showed (99\%) similarities with Burkholderia gladioli (FJ865580).

Table 1. Properties of the soil samples

\begin{tabular}{|c|c|c|c|c|c|}
\hline Sample & $\mathbf{p H}$ & $\begin{array}{c}\text { Organic matter } \\
\qquad(\mathrm{g} / \mathrm{kg})\end{array}$ & $\begin{array}{r}\text { sand } \\
(\%)\end{array}$ & $\begin{array}{l}\text { Silt } \\
(\%)\end{array}$ & $\begin{array}{r}\text { Clay } \\
(\%)\end{array}$ \\
\hline 1 & 6.58 & 28.3 & 80.61 & 6.64 & 12.75 \\
\hline 2 & 6.76 & 26.7 & 84.00 & 9.00 & 7.00 \\
\hline
\end{tabular}

\section{Biodegradation of profenofos}

\section{Degradation in liquid culture media}

Under aerobic conditions, profenofos degradation by both bacterial isolates was monitored by GC for a period of $96 \mathrm{~h}\left(\right.$ Fig. $\left.1 \mathrm{a}_{1} \& \mathrm{a}_{2}\right)$ in liquid culture media.
Both Pseudomonas putida $W$ and Burkholderia gladioli effected very rapid degradation of profenofos, added to the mineral salts medium as a sole carbon source.

Rapid degradation began shortly after 6 hours of incubation under aerobic conditions, suggesting that a constitutively expressed enzyme(s) was involved in the degradation of profenofos. The degradation of profenofos supported cell growth, indicating that isolated strains could utilize profenofos as a carbon source.

After 6 h, 27.77\% and $19.92 \%$ of pesticide had rapidly removed by Pseudomonas putida $W$ and Burkholderia gladioli respectively followed by a slower decrease of profenofos with longer incubation times. After $96 \mathrm{hrs} 92.37 \%$ pesticide was removed by Pseudomonas putida showing its ability to degrade op compounds in liquid media while in case of Burkholderia gladioli results were $87.58 \%$.

\section{Degradation of profenofos in soils}

The soil sample, previously used to isolate profenofos degrading bacteria, was used in this study. The soils characteristics are given in the Table 2. The standard error was within $5 \%$ of the mean.

The addition of isolated strains to soils resulted in a more rapid rate of profenofos degradation than that by control (non-sterilized soil and sterilized) soils. Degradation of profenofos in control sterilized soils (without inoculation) was minimal where less than $16 \%$ of the applied concentration was degraded in 25-day incubation studies (Fig. $1 b_{2}$ ). Degradation of profenofos was significant in control non-sterilized (without inoculation) soil where $84 \%$ degradation was recorded in 25 days. Fig. $1 b_{1} \& b_{2}$ demonstrates that approximately $70 \%$ profenofos was degraded within 5 days but the degradation reaches 96.06 and 99.37within 25 days by Pseudomonas putida and Burkholderia gladioli respectively. This suggested the same fashion of degradation by both strains in soil and as well as in liquid media such as in first phase rapid steep decline in concentration of the profenofos followed by slower degradation. 
Table 2. Morphological and Biochemical characteristics of profenofos degrading isolated bacterial strains

\begin{tabular}{lll}
\hline Biochemical Test and staining & Isolate W & Isolate Y \\
\hline Gram straining & Negative & Negative \\
Oxidase & Positive & Negative \\
Catalase & Positive & Positive \\
Indole test & Positive & Negative \\
Methyl red & Negative & Negative \\
Voges-Proskauer & Positive & Positive \\
Citrate & Positive & Negative \\
H 2 S production & Positive & Negative \\
Urease & Negative & Negative \\
Glucose ,Sucrose & Positive & Positive \\
Lactose & Positive & Negative \\
Manitol & Negative & Positive \\
Methanol, Ethanol, Butanol, Isobutanol & Negative & Positive \\
Denitrification & Positive & Negative \\
Cell type (shape) & rods & Curve rods \\
Color(colony in FTW media) & white & Yellow \\
Elevation & flat (irregular) & convex (entire) \\
Surface & Not smooth & Smooth \\
\hline
\end{tabular}

\section{DISCUSSIONS}

Isolation of bacterial strain through enrichment technique has been extensively used for the study of biodegradation of pesticides (31). The results obtained in this study were in agreement with earlier reports that indicated the involvement of pseudomonas putida in the degradation of organophosphorus insecticides like chlorpyrifos (4), methylparathion (27), phosphonate (7) parathion (13), ethoprophos (19) and glyphosate (34).

Members of the genus Burkholderia are versatile organisms that occupy a wide range of ecological niches. These bacteria are exploited for biocontrol, bioremediation and plant growth promotion purposes, but safety issues regarding human infections, especially in cystic fibrosis patients, have not been solved. Many members of genus Burkholderia have been discovered as pesticide degrader, For example, the species B. kururiensis (36), B. sacchari (5), B. phenoliruptrix 11(6), B. terrae (16) and B. cepacia (2) but there have been only a few previous reports on the ability of biodegradation of Burkholderia gladioli.

Degradation of pentachlorophenol (30) and glyphosate (20) has been early reported. To our knowledge this is very first report on ability of Burkholderia gladioli to degrade profenofos.

OPH gene in Burkholderia sp. Strain NF100 has been extensively studied (29), similarly esterase gene was found in Burkholderia gladioli (25), as previous reports clearly stated that esterase gene can be responsible for the breakdown of ester bond in organophosphate pesticide which may be the reason for biodegradation of profenofos.

In the natural environment, the competition for carbon sources is immense and the utilization of profenofos as an energy source by this bacterium provides it with a substantial 
competitive advantage over other microorganisms. Successful removal of pesticides by the addition of bacteria (bioaugmentation) had been reported earlier for many compounds, including parathion (37), coumaphos (3) and ethoprop (19).
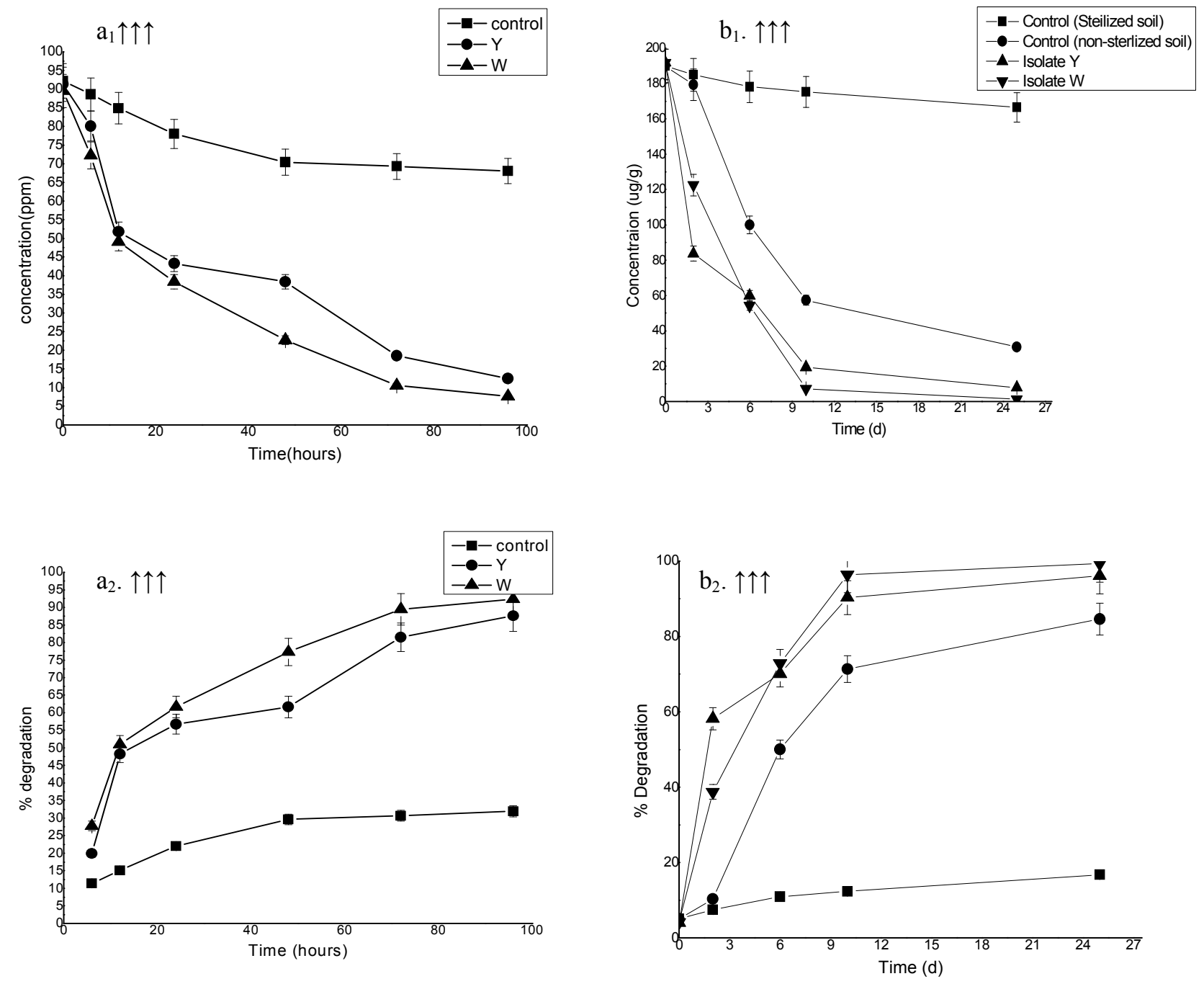

Figure 1. Degradation kinetics of profenofos by bacterial strains; $\left(a_{1}\right)$ degradation in liquid batch culture media (FTW amended with profenofos) at different time interval; - - control, - $\bullet-Y,-\boldsymbol{\Delta}-\mathrm{W} ;\left(\mathrm{a}_{2}\right) \%$ degradation of profenofos at different

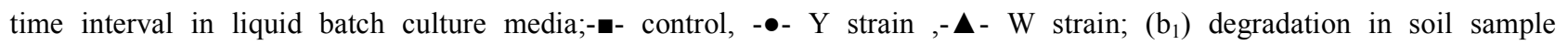

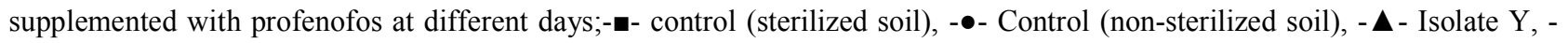

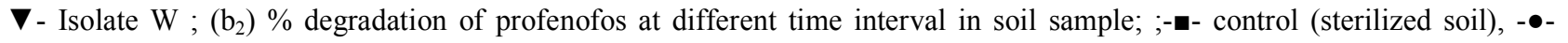
Control (non-sterilized soil), - $\mathbf{\Delta}$ - Isolate Y - $\boldsymbol{\nabla}$ - Isolate W 


\section{ACKNOWLEDGEMENTS}

This work was supported by both the National Key Technology R \& D Program of China (2008BADA7B03) and the City Key Technology R \& D Program of Wuhan in China (200720422150). The authors are grateful to Mr. Shamba Chatterjee, Prof. S. H. Qi, Dr. G. L.Sheng and their students for their valuable suggestions as well as technical support. The authors would like to thank to Dr.Julia Ellis Burnet for her helpful comments on the manuscript.

\section{REFERENCES}

1. Akerblom, N. (2004). Agricultural pesticide toxicity to aquatic organisms: a literature review. Sveriges Lantbruks Univ., Uppsala, 2004, pp. 31

2. Anthony, R.; Smith, W.; Carol, A.B. (2008). Induction of enzymes of 2, 4 dichlorophenoxyacetate degradation in Burkholderia cepacia $2 a$ and toxicity of metabolic intermediates. Biodegradation., 19, 669-681.

3. Barles, R.W.; Daughton, G.C.; Hsieh, D.P.H. (1979). Accelerated parathion degradation in soil inoculated with acclimated bacteria under field conditions. Arch. Environ. Contam. Toxicol., 8, 647-660.

4. Brajesh, K.S.; Allan, W.; Alun, W.; Denis, J.W. (2004). Biodegradation of Chlorpyrifos by Enterobacter Strain B-14 and Its Use in Bioremediation of Contaminated Soils, American Society for Microbiology, Appl. Envir. Microbiol., 27, 4855-4863.

5. Bramer, C.O.; Andamme, P.V.; da Silva, L.F.; Gomez, J.G.; Steinbuchel, A. (2001). Burkholderia sacchari sp. nov. a polyhydroxyalkanoate-accumulating bacterium isolated from soil of a sugar-cane plantation in Brazil. Int. J. Syst. Evol. Microbiol., 51, 1709-1713.

6. Coenye, T.D.; Henry, D.P.; Speert Vandamme, P. (2004). Burkholderia phenoliruptrix $s p$. nov. to accommodate the 2,4,5trichlorophenoxyacetic acid andhalophenol-degrading strain AC1100 System. Appl. Microbiol., 27, 623-627.

7. Cook, M.A.; Christian, G.; Daughton Martin, A. (1978). Phosphonate Utilization by Bacteria. J. Bacteriol., 1, 85-90.

8. Costa, L.G.; Cole, T.B; Jansen, K.L.; Furlong, C.E. (2008). Paraoxonase (pon1) and Organophosphate toxicity, Springer chap 13 pages 209-220.

9. Dave, K.I.; Miller, C.E.; Wild, J.R. (1993). Characterization of organophosphorus hydrolase and the genetic manipulation of the phosphotriesterase from Pseudomonas diminuta. Chem. Biol. Interact., 87, 55-68.

10. Focht, D.D. (1994). Microbiological procedures for biodegradation research (R.W. Weaver et al. (ed.) Methods of soil analysis. Part 2. SSSA. Book Ser. 5. pp. 407-426.
11. Fukuto, T.R. (1990). Mechanism of action of organophosphorus and carbamate insecticides. Environ. Health Perspect., 87, 245-254.

12. George, M.G. (2005). Gammaproteobacteria. Bergey's Manual of Systematic Bacteriology, Vol. 2 (Don J. Brenner Noel R Krieg \& James T. Staley eds), pp. 323-378, Springer USA.

13. Gilbert, E.S.; Walker, A.W.; Keasling, J.D. (2003). A constructed microbial consortium for biodegradation of the organophosphorus insecticide parathion Appl Microbiol Biotechnol., 61, 77-81.

14. Goldberg, J.B.; Ohman, D.E. (1984). Cloning and expression in Pseudomonas aeruginosa of a gene involved in the production of alginate, J. Bacteriolo., 158, 1115--1121.

15. Herman, D.C.; Frankenberger, W.T. Jr. (1999). Bacterial reduction of perchlorate and nitrate in water. J. Environ. Qual., 28, 1018-1024

16. Hiroaki, I.; Kazuya, A.; Yoshie, H. (2007). Isolationand characterization of a new2, 4-dinitrophenol-degrading bacterium Burkholderia sp. strainKU-46 and its degradation pathway. FEMS Microbiol. Lett., 274, 112-117.

17. Horne, I.; Harcourt, R.L.; Sutherland, T.D.; Russel, R.J.; Oakeshott, J.G. (2002). Isolation of a Pseudomonas monteilli strain with a novel phosphotriesterase. FEMS Microbiol. Lett., 206, 51-55.

18. Horne, I.; Sutherland, T.D.; Harcourt, R.L.; Russell, R.J.; Oakeshott, J.G. (2002). Identification of an opd (organophosphate degradation) gene in an Agrobacterium isolate. Appl. Environ. Microbiol., 68, 33713376.

19. Karpouzas, D.G.; Walker, A. (2000). Factors influencing the ability of Pseudomonas putida strains epI and II to degrade the organophosphate ethoprophos. J. Appl. Microbiol., 89, 40-48.

20. Kuklinsky, S.J.; Luiz, A. W.; Mendes, R.; Pizzirani, I.; Kleiner, A.A.; Azevedo, J.L. (2005). Isolation and characterization of endophytic bacteria from soybean (Glycine max) grown in soil treated with glyphosate herbicide. Plant and soil., 273, 91-99.

21. Kumar, S.; Mukerji, K.G.; Lal. (1996). Molecular aspects of pesticide degradation by microorganisms. Crit. Rev. Microbiol., 22, 1-26.

22. Martinez, T.; Salmeron, M.V.; Gonzalez, V. L. (1992). Effect of an organophosphorus insecticide, profenofos, on agricultural soil microflora. Chemosphere 24, 71-80.

23. Mulbry, W. (2000). Characterization of a novel organophosphorus hydrolase from Nocardiodes simplex NRRL B-24074. Microbiol. Res., $154,285-288$

24. Mulbry, W.; Karns, W.; Kearney, J.C.; Nelson, P.C.; McDaniel, J.O.; Wild, C.S. (1986) Identification of plasmid-borne parathion hydrolase gene from Flavobacterium sp. by southern hybridization with opd from Pseudomonas diminuta. Appl. Environ. Microbiol., 51, 926-930.

25. Petersen, E.I.; Valinger, G.; Solkner, B.; Stubenrauch, G.; Schwab H. (2001). A novel esterase from Burkholderia gladioli which shows high deacetylation activity on cephalosporins is related to $\beta$-lactamases and DD-peptidases. J. Biotechnol., 9. 1, 11-25.

26. Prescott, L.M.; Harley \& Klein. (2002). Microbial Nutrition. Microbiology 5th ed. page 101-110. 
27. Rani, N.L.; Lalitha-Kumari, D. (1994). Degradation of methyl parathion by Pseudomonas putida. Can. J. Microbiol., 15, 984-987.

28. Ronald, M. (2000). Atlas Handbook of microbiological media 2000, page 905, CRC Press USA.

29. Tago, K.; Yoenezawa, S.; Ohkouchi, T.; Ninomiya, T.; Hashimoto, M.; Hayatsu ,M. (2006). A Novel Organophosphorus Pesticide Hydrolase Gene Encoded on a Plasmid in Burkholderia sp. Strain NF100. Microbes Environ., 21, 53-57.

30. Takashi, N.; Takayuki M.; Yoshikatsu S.; Isamu Y. (2004). Biotransformation of pentachlorophenol by Chinese chive and a recombinant derivative of its rhizosphere-competent microorganism, Pseudomonas gladioli M-2196 Soil Biology and Biochemistry., 36, 787-795.

31. Tatiane, M.S.; Maria, I.S.; André, M.M.; Fabiana, D.A.; Sônia, A.V.P.; Paulo, R. F.; Marcelo, D.C.; Emanuel, C.B.; Carneiro Marcos, P. (2007). Degradation of 2, 4 D herbicide by microorganisms isolated from Brazilian contaminated soil. Brazil. J. Microbiol., 38, 522-525

32. US EPA (2000). The HED chapter of the registration eligibility decision document (RED) for profenofos EPA 738-F-00-005.
33. WHO (2004). The WHO recommended classification of pesticides by hazard and guidelines to classification 2004, WHO/PCS/90.1, World Health Organization, Geneva, Switzerland

34. Yi-Cheng, S.; Yan-Cheng, C.; Zhe-Xian, T.; Feng, M.L.; Xin-Yue, W.; Jing Zhang, H.; Hanada, S.; Shigematsu, T.K.; Shibuya, Y.; Kamagata, T.; Kanagawa \& Kurane, R. (2000). Burkholderia kururiensis sp. nov. a trichloroethylene (TCE)-degrading bacterium isolated from aquifer polluted with TCE. Int. J. Syst. Evol. Microbiol., $50,743-749$.

35. Zamy, C.; Mazellier, P.; Legube, B. (2004). Phototransformation of selected organophosphorus pesticides in dilute aqueous solutions. Water Research., 38, 2305-2314.

36. Zhang, Z.L.; Xiao, M.L.; Niamh, G.; David, N.; Dowling, ; Yi-Ping, W. (2005). Novel AroA with High Tolerance to Glyphosate, Encoded by a Geneof Pseudomonas putida 4G-1 Isolated from an Extremely Polluted Environment in China App. Env. Microbiol., 71.8, 4771-4776.

37. Zhongli, C.; Shunpeng, L.; Guoping, F. (2001). Isolation of methyl parathion-degrading strain M6 and cloning of the methyl parathion hydrolase gene. Appl. Environ. Microbiol., 67, 4922-492. 